\title{
Development of Program to Enhance Team Building Leadership Skills of Primary School Administrators
}

\author{
Boonchauy Sairam ${ }^{1}$, Chaiyuth Sirisuthi ${ }^{1} \&$ Kanjana Wisetrinthong ${ }^{1}$ \\ ${ }^{1}$ Faculty of Education, Mahasarakham University, Thailand \\ Correspondence: Boonchauy Sairam, Faculty of Education, Mahasarakham University, Thailand. E-mail: \\ robinram99@gmail.com
}

Received: February 13, 2017

Accepted: March 21, 2017 Online Published: June 27, 2017

doi:10.5539/ies.v10n7p143

URL: https://doi.org/10.5539/ies.v10n7p143

\begin{abstract}
Team building leadership skills are important to understandings of how the primary school administrators might work towards creating more effective teamwork in the school. This research aimed 1) to study the components of team building leadership skills needed for primary school administrators, 2) to examine the current states and desirable conditions and needs for team building leadership skills of primary school administrators, 3) to develop team building leadership skills for primary school administrator enhancement program, and 4) to explore the efficiency level of team building leadership skills of primary school administrator enhancement program by using the developmental research process. Sampling and data collection were as follows: step one, collect data from the relevant literature, publications, online research and academic databases regarding leadership and team building skills. Moreover, the components of team building leadership skills were verified by 9 experts. Step 2, 379 primary school administrators of the planning programs were consulted for studying current states and desirable characteristics of team building leadership skills and needs in development of primary school administrator enhancement program. Step 3 required 9 experts to evaluate and comment on the program. Step 4 required a group of 20 primary school administrators under the Office of Ubonratchathani Education Service Area Zone 2 for efficiency assessment. Research instruments were a questionnaire and an evaluation form. Statistics used in data analysis and verification were percent, means, standard deviation, Modified Priority Needs Index ( $\left.\mathrm{PNI}_{\text {modified }}\right)$ and Independent t-test. The research results showed that team building leadership skills of primary school administrators' enhancement program consisted of 5 toolkits. The application of the program showed that the participants receiving the development of team building leadership skills of primary school administrators' enhancement program had higher team building leadership skills after the development than before. The primary school administrators manage teamwork more efficiently and the overall progress of team building successfully.
\end{abstract}

Keywords: development of program, team building leadership skills enhancement program, team building leadership skills, teamwork, primary schools

\section{Introduction}

\subsection{Challenges}

The effects of globalizations and changes in science and information technology on education bring rapid within learning systems across the world as ideas, values and knowledge, information-based society and producing a shift in society from industrialization towards. It reflects the effect on the roles of students and teachers, school administrators and the future citizens of the world into global citizens intelligent. At the same times, the internationalization of education can be linked to various internal and external changes in the international system. Externally, there have been changes in the labor market, which have resulted in calls for more knowledge and skilled workers, and workers with deeper understandings of languages, cultures and business methods all over the world. Education is becoming more invaluable to individuals on globalizations and technological that advancements delivering and increasing access to educational administration subsequently subjects should reflect this global development outlook (Ministry of Education, 2013).

Based on the National Education Act B.E. 2542 (1999) schools are responsible for decentralized educational management at implementation level. In the provision of basic education schools are required to grant all individuals with equal rights and opportunities to receive basic education provided by the State for provided on a 
nationwide. Moreover, provision of education is based on the principles of lifelong education for all; participation in educational provision from all segments of society; and continuous development of the bodies of knowledge and learning processes. In this regard, all basic education schools have to conduct their educational administration and management in an accountability and responsibility to the educational reform which focus via participation from all parties and the utilization of organizational resources to maximize the educational quality development in a cost-effective manner (Office of the Basic Education Commission, 2013). Considering as an educational organization, school administrators, teachers and educational personnel must be given focus via the improvement of work based skills and quality, educational resources and investment for powering up educational resources into the system, quality assurance by validating internal and external audits and educational media and technology for standardization of a variety of media and technology (Ministry of Education, 2013). The achievement to reform education, there were all of the enormous impacts on educational leadership. One of the most obvious effects will be the fact that societies will increasingly expect that educational leaders will be able to cope with the increasingly difficult and complex challenges that arise in the 21 st century. They will also require school administrators to uphold core principles of visionary capacity, new professional leadership skills, instructional design, assessment literacy and crisis management in this new global era that necessitate the emergence of varieties of new and important trends in educational management practices and leadership skills paradigms (Office of the Education Council, 2014). In this situation of high expectations of parents and societies, those schools administrators have an enormous responsibility and accountability on the role of outstanding leaders. Effective schools leaders are keys to build performance teamwork for the purpose of effective performance of teacher who work cooperatively together, coordinate their roles and functions to accomplish the common goals and tasks. In consequence, the achievement of efficient cooperative working will bring organizational development school administrators need to adapt itself and learns how to learn by seeking new working techniques in order to respond the social needs (Phanich, 2012). Ngamkanok (2007) reported in his work that the school administrator pays attention to effective team building; the team will help create effective persons because teamwork would encourage the group members to share their learning, as well as getting the new working models. As a result, this situation creates more qualified team building leadership skills in organization that would help the school administrators and teachers working together at schools and development of educational institutions to be growth continually.

\subsection{Team Building Leadership Skills}

Leadership involves exerting influence over other members of a group or organization. Therefore, leadership involves helping a group or organization achieve its goals. Combining these two key characteristics, leadership as the capability of an individual to exercise influence and control over other members to help a group or organization achieve its goals (George \& Jones, 2012). Leadership is the ability to inspire confidence and support among the people who are needed to achieve organizational goals. Leadership involves having a vision of what the organization can become, requires eliciting cooperation and teamwork from a large network of people and keeping the key people in that network motivated (DuBrin, 2012). Leadership skills are an essential component in positioning executives to make thoughtful decisions about their organization's mission and goals, and properly allocate resources to achieve those directives. Valuable leadership skills include the ability to delegate, inspire and communicate effectively (West, 2012). In Thailand, the idea of team building leadership skills were inefficiency; the team not have clear goals or performance metrics, the team be composed of the wrong people with the wrong set of skills for the task at hand, the team's dynamics not foster creativity and good decision making, the team not have known how to solve its own problems and improve performance. The school administrators were poor team performance due to a team's inability to systematically engage in team-building activities, team processes for evaluating, team performance and engaging in problem-solving activities that lead to improved team performance. Lack of research on this subject has resulted ineffectively team building leadership skills and become the major concern of the teamwork performed today were done in the schools working (Aemaeim, 2009). Chareonwongsak (2013) presented relevant ideas of team building leadership skills development and action learning can be practiced and improved. In this situation, a group of people are working on a problem for which there is no known solution. As they work together, everyone is equally capable of identifying the potential solution; this is what occurs in the action learning process. As a result, every leadership skill can be developed deeply and quickly in action learning. Furthermore, action learning is part of their leadership skills development program. Since developing the leadership skills of each group member is critical not only for the long-term benefit of the organization, but also to better enables the group to become smarter and work better together, it is highly advised that leadership skills development is a formal and integral part of all action learning programs. 


\subsection{Team Building Leadership Skills of Primary School Administrators}

In currently, School leaders enhances team members set goals, make decisions, communicate, manage conflict, and solve problems in a supportive, trusting atmosphere in order to accomplish their objectives. They are aware of their own strengths and weaknesses and have the ability to make changes when they need to improve their performance working outcomes (Everard, Morris, \& Wilson, 2004). School administrators are essential and need to have leadership skills that include team building skills in educational administration and development. School leaders need to acquire team building leadership skills to making high-performing teams are those with members whose skills, attitudes, and competencies enable them to achieve team goals (Jhunthai, 2015). Developing team building leadership skills necessitate the appreciation of several problems. First, under valuing of team building leadership skills were caused by lack of knowledge of team building leadership skills, its influences over the performance of the school organization development. Second, there is a lack of knowhow of team building leadership skills development. The state still takes place old school leadership skills development for school administrators which is not applicable in present contexts and modernization situations. Third, the training program of leadership skills development instead mistake for school administration that aims to improve the roles and duty of management but not integrated personnel leadership skills (Yukl, 2010). Kumso (2015) reported in his work that in many schools the school administrators and teachers work in isolation, school administrators try to accomplish tasks alone, and the responsibility for implementing new ideas falls on the individual. However, working together in a team is often a more effective way to accomplish important tasks. Thus, teamwork is central in the efficient and effective management of schools and it is a vital force in improving schools (Polprateep, 2015). Moreover, few trends have influenced jobs more than the movement to introduce teams in the workplace. Building effective teams requires long standing principles regarding stages of team development include how members develop norms and cohesiveness, share roles, make decisions, communicate with one another, and handle conflicts. And importantly, the administrators know that teams experience different process challenges as they pass through the stages of team building as forming, storming, norming, performing, adjourning and dynamics. Team members and leaders need to be mindful of the potential team dysfunctions including social loafing and groupthink (Whetten \& David, 2011; Schermerhorn, 2015; Lunenburg, 2015). Furthermore, Thai primary school administrators need to improve their educational administration and development focus via the school context. The primary school administrators need team building skills, team members, and team consultants' specific guidance on how to improve team performance. Although the team building activities that they propose may be particularly well suited for poorly performing or dysfunctional teams, they also can transform average or even good teams into great teams (Hallinger \& Lee, 2014).

According to the reasons mentioned, the researcher is interested in Development of Program to Enhance Team Building Leadership Skills of Primary School Administrators in order to investigate and develop team building leadership skills that to be able achievement teamwork and support quality education for Thai primary school administrators.

\section{Research Objectives}

This research aimed 1) to study the components of team building leadership skills needed for primary school administrators, 2) to examine the current states and desirable conditions and needs for team building leadership skills of primary school administrators, 3) to develop team building leadership skills for primary school administrator enhancement program, and 4) to explore the efficiency level of the team building leadership skills of primary school administrator enhancement program.

\section{Method and Instrument}

This research and development is divided into 4 steps;

Step 1: Studied and determined the components of team building leadership skills. It examined the documents, concepts, theories and relevant research on team building leadership skills development. The components were determined and evaluated by 9 experts. The research tools consisted of the evaluation format. Statistics used in data analysis were mean and standard deviation.

Step 2: Investigating current condition of team building leadership skills and needs in development of primary school administrator enhancement program. The survey on the sample group consisted of 379 primary school administrators by using a 5-rating scale questionnaire. Data were verified by finding Item Total Correlation and Cronbach' Alpha Coefficient. Statistics used to analyze data were percent, mean, standard deviation and Modified Priority Needs Index ( $\left.\mathrm{PNI}_{\text {modified }}\right)$. 
Step 3: Developing team building leadership skills of the primary school administrator enhancement program. The collected data from step 2 were used as a guideline in developing team building leadership skills of the primary school administrator enhancement program and creating a respective manual. The program was evaluated and commented upon by 9 experts employing a 5 rating scale questionnaire. Statistics used in data verification were content validity, mean and standard deviation.

Step 4: Applying the team building leadership skills of the primary school administrator enhancement program. The invented program was applied among the sample group of 20 primary school administrators under the Office of Ubonratchathani Education Service Area Zone 2. They voluntarily participated in the program, evaluated the program via 2 evaluation forms: self-evaluation and by teacher evaluation. Statistics used in data verification were content validity, mean and standard deviation.

\section{Results}

\subsection{Investigating Theory and Relevant Researches, Team Building Leadership Skills Needed for Primary School Administrators}

There were 5 main components and 21 sub-components discovered as follows:

Forming consisted of team goals, team objectives, team members and team roles.

Storming consisted of team development, effective communication, good relationship and creative confliction.

Norming consisted of shared leadership, share vision, trust and cohesiveness.

Performing consisted of team planning, motivation, creative thinking, participation, team environment, decision making and solving problems.

Team feedback and dynamic consisted of team process and team learning.

\subsection{Investigating Desirable Conditions and Needs in Development of the Team Building Leadership Skills of Primary School Administrator Enhancement Program}

It was found that the current states on team building leadership skills of primary school administrators were implemented at a moderate level overall and in each aspect and the desirable states were implemented at the highest level in overall and in each aspect. As regards the need priority $\left(\mathrm{PNI}_{\text {Modified }}\right)$ in developing the team building leadership skills of primary school administrators under the Office of Basic Education Commission was ranked from highest to low were norming, performing, forming, team feedback and dynamic and storming.

\subsection{Developing the Team Building Leadership Skills of Primary School Administrator Enhancement Program}

The developed program of the team building leadership skills of primary school administrators consisted of 2 items 1) the program of team building leadership skills of primary school administrators enhancement contained the following: 1) program principles; 2) program objectives; 3) program resources; 4) program toolkits, which consisted of 5 toolkits as the forming toolkit, storming toolkit, norming toolkit, performing toolkit and team feedback and dynamic toolkit in which there were 5 parts (introduction, background, principle to practice, lesson summary and evaluation) inclusive in each toolkits. The program toolkit to develops team building leadership skills of primary school administrators were various in order to create a body of knowledge, understanding, skills for team building leadership skills and continuous self - development. The toolkits consisted of 4 parts, taking 240 hours of training: part 1 was 25 hours of self - learning toolkit and pretest self - assessment. Part 2 was 55 hours of training courses and workshops presented in five activity toolkits. Part 3 was 144 hours of practitioner implementation and challenge assignments. Part 4 was 16 hours of feedback and follow up. 5) measurement and evaluation 2) the program manual, which contained 4 parts: introduction, the team building leadership skills of primary school administrators enhancement program, the application of team building leadership skills development and the program evaluation. Developing the team building leadership skills of primary school administrator enhancement program is described as Figure 1 below. 


\section{Self-learning Activity toolkit and Self-assessment ( 25 hours)}

1.1 Self-leanning five activity toolkits before receiving the Training courses and Workshops regarding team building leadership skills enhancement program.

\subsection{Pretest Self-Assessment}

\section{Training courses and Workshops (55hours)}

2.1 Training courses and Workshops regarding team building leadership skills enhancement program through the program manual consisted of five toolkits. (40 hours)

Toolkit l: Forming

Set 1 Team goals, Set 2 Team objectives, Set 3 Team members, Set 4 Team roles

\section{Toolkit 2: Storming}

Set 1 Team development, Set 2 Effective communication, Set 3 Good relationship

Set 4 Creative confliction

\section{Toolkit 3: Norming}

Set 1 Shared leadership, Set 2 Share vision, Set 3 Trust, Set 4 cohesiveness

\section{Toolkit 4: Performing}

Set 1 Team planning, Set 2 Motivation Set 3 Creative thinking, Set 4 Participation,

Set 5 Team environment, Set 6 Decision making, Set 7 Solving problems

\section{Toolkit 5: Team feedback and dynamic}

Set 1 Team process, Set 2 Team learning 15 hours

2.2 Knowledge management and lesson summary, Site visit and discussion of role models

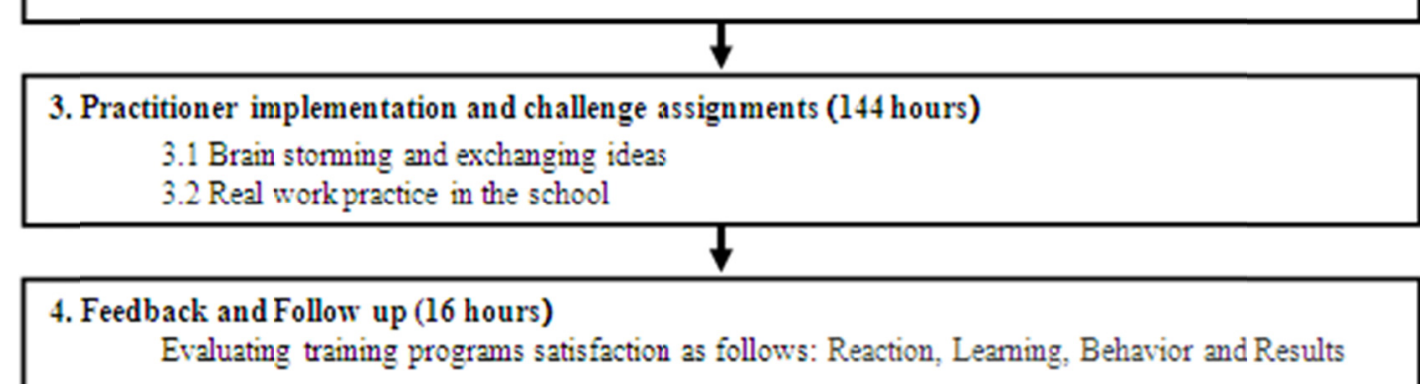

Figure 1. Developing the team building leadership skills of primary school administrator enhancement program

4.4 Results of the Team Building Leadership Skills of Primary School Administrator Enhancement Program Application

The primary school administrator had 12.00 out of 30 score points at average before receiving the development equate to 42.28 percent, and had 26.50 out of 30 score points after the development equated to 88.46 percent. The after development score point was higher than the before development average score at the statistical significant level of .01 and passed 80 percent standard set. 
The evaluation of the team building leadership skills level of primary school administrator, measured by the administrators and teachers, revealed that the post-development team building leadership skills level was higher than the pre-development level in all aspects. Moreover, the feedback and follow up-period evaluation of the team building leadership skills level was higher than the post- development level in all aspects.

The evaluation of the team building leadership skills enhancement program in terms of satisfaction was at a very high level overall. When considering each aspect ranking from high to low, the elements of training venue and facilities and development activities toolkits were at a very high level, while the content and training document was at a high level.

\section{Discussion}

The results of the development research on team building leadership skills of primary school administrator enhancement program presented interesting issues and need to be discussed as follows:

\subsection{Team Building Leadership Skills Needed for Primary School Administrators}

There were 5 main components and 21 sub-components discovered.

\subsection{The Components and Sub-Components on Team Building Leadership Skills as Described below}

Forming contains 4 Sub-element as 1) team goals setting, 2) team objectives setting, 3) team members selection and 5) team roles assignment. This is consistent with Whetten \& David (2011) saying that team is faced with the need to become acquainted with its members, its purpose, and its boundaries its relationships, its clarity of direction are needed from team leaders as suggested in the researches of Halverson and Tirmizi (2008), Woodcock and Francis (2008) and Biech (2008).

Storming contains 4 Sub-element as 1) team development, 2) effective communication, 3) good relationship and 4) creative confliction, as supported by the research of Monique \& Zeebroeck (2010) which found that building team power moves an excursion to learn how to unleash the collaborative genius of work teams by concentrating on skill areas as also explained by Dyer Jr., J. Dyer, and W. Dyer (2013) team building skill were particularly well suited for poorly teamwork or dysfunctional teams; furthermore, it also can transform average or even good teams into great teams as also suggested by Whetten and David (2011), Dyer, Jeffrey, and William (2013), Schermerhorn (2015).

Norming contains 4 Sub-element as 1) shared leadership, 2) share vision, 3) trust and 4) cohesiveness. This is consistent with Levi (2014) revealing that team is faced with creating cohesion and unity, differentiating roles, identifying expectations for members, and enhancing commitment to a vision are needed from team leaders. Robbins (2013) described that norms are extremely powerful and are capable of significantly modifying a performance prediction based solely on ability and level of personal motivation as also suggested by Jones (2004), Kohn (2007), Parker (2007), Biech (2008), Sheard, A. Kakabadse, and N. Kakabadse (2009), Schermerhorn (2015).

Performing contains 7 Sub-elemet as 1) team planning, 2) motivation, 3) creative thinking, 4) participation, 5) team environment, 6) decision making and 7) solving problems. Kayser (2011) described that team is faced with the need for continuous improvement, innovation, speed, capitalizing on core competencies; sponsoring team members' new ideas, orchestrating their implementation, and fostering extraordinary performance are needed from the team leaders. Chris (2010) explained that team members have become comfortable with each other and their project effectively working as well as the team really success to perform competently as also suggested by Parker (2007), Biech (2008), Woodcock and Francis (2008), Dyer Jr., J. Dyer, and W. Dyer (2013), Schermerhorn (2015).

Team feedback and dynamic contains 2 Sub-element as 1) team process and 2) team learning. This is consistent with Eckes (2003) revealing that team feedback and dynamics are as the motivating and driving forces that propel a team toward its goal or mission. Edmondson (2013) indicating that the team trying to innovate must figure out a way to learn as quickly as possible from early experiences and take for granted an execution-oriented frame for getting work done as a learning process is an essential driver of innovation as consistent with findings from Tranter and Percival (2006), Jennings (2008), Marquardt (2011), Dyer Jr., J. Dyer, and W. Dyer (2013), Schwarz (2013), Schermerhorn (2015).

\subsection{The Current and Desirable Condition of Team Building Leadership Skills of Primary School Administrator}

As for the current and desirable states of team building leadership skills of primary school administrator in the study from 379 school administrators viewed that the current states of team building leadership skills were moderate and the desirable states were at the highest level. Considering the need priority concerning team 
building leadership skills was ranked from highest to low were norming, performing, forming, team feedback and dynamic and storming.

This may result because the primary school administrators are able to adapt themselves to teamwork and changes, apply empirical evidence in teamwork and team development, effective communication, good relationship and creative confliction, accept their own mistakes and know how to improve appropriate decision making, adjustment, create values and culture in the school organization, cooperate with internal and external organizations. However, the primary school administrators have team building leadership skills at a lower level in all aspects compared to from the opinions collected from the school administrators. This may be because the primary school administrators had limited on team building knowledge of school management and the perspective of teamwork was different. It was also shown that the school administrators agreed that team building leadership skills level was lower compared to other skills investigated. This might result from the primary school administrator lacking team building as best practices, team leadership skill, team management skill and colleagues' respect and recognition. As in the aspect of team building leadership skills, the primary school administrator showed their lack of paying attention in balancing between teamwork and personal life, confidence, clear organization directions and community participation in the future of teamwork planning. The organization research and development plan is discontinued and the resource management is inappropriate and inefficient. There are lacking of a checking system and frequent educational improvement. There is also to a certain degree, no democratic teamwork environment. Considering the aspect of team building leadership skills, it is revealed that the school administrators fail to discuss building and leading high performing teams in school organization, check teamwork results and evaluate the information gained to develop and improve their jobs achievement, feedback and exchange knowledge between executives and operators. Team building is important aspect of working today. Many organization use teams to complete projects and building an effective team are necessary to complete a project. Teams are most successful when school administrators able to help see them through some of the more difficult stages of the team-building process. The desirable teamwork condition in schools is the existence of clarity of the executives, ability to direct new directions, organizational culture and identity, participation in empirical data collection with colleagues, providence of appropriate learning environment, motivation for others to see significance and common objectives. They request the school administrators to have strategies and innovation in teamwork development within the organization, common understanding with plans and readiness for meetings, before working on projects. This would facilitate all parties. This is consistent with Aemaeim (2009), who mentioned in her research on Equation Model of Team Building leadership of Administrators in the Secondary School, which presented the leadership skills of team building at a high level. The administrators with different genders and ages are have different levels of team building leadership while the ones that administrated in different school sizes and with different years of work experience had levels of team building leadership that were different at statistically significance level of .05. Sreesumphun (2010) conducted a research on the Effective Team building Skills of School Administrator in Secondary School and found that team building skills at a high level. The school administrator in secondary school based clear goals; decision making authority; accountability and responsibility; effective leadership; training and development; provision of resources; organizational support; and rewards for team success as overall and by each aspect was at a very high level. The other work of Cheamchoi (2012) research on the Innovation of Team Building in The 21st Century School, which presented the principal's roles, duties and responsibilities of team building at a high level. The principal pay roles, duties and responsibilities of team building for high-quality instructional programs and, ultimately, enhancing student achievement as overall and by each aspect was at a very high level. This is consistent Jhunthai (2015) research titled The Development of Program of Team Development in Municipality School as the current condition of the administrators in municipality school as overall and by each aspect at a high level. The priority need in developing based team leadership skills as overall and by each aspect was at a very high level.

\subsection{The Evaluation of Team Building Leadership Skills of Primary School Administrator Enhancement Program}

The evaluation results conclude that the developed program of team building leadership skills of primary school administrator enhancement program consisted of 2 items: 1) the program of team building leadership skills of primary school administrators enhancement contained the following: 1) program principles; 2) program objectives; 3) program resources; 4) program toolkit, which consisted of 5 toolkits as the forming toolkit, storming toolkit, norming toolkit, performing toolkit and team feedback and dynamic toolkit in which there were 5 parts (introduction, background, principle to practice, lesson summary and evaluation) inclusive in each activity toolkit. The program toolkit to develops team building leadership skills of primary school administrators were various in order to create a body of knowledge, understanding, skills for team building leadership skills and 
continuous self-development. The toolkits consisted of 4 parts, taking 240 hours of training; 2) the program manual, which contained 4 parts: introduction, the team building leadership skills of primary school administrator enhancement program, the application of team building leadership skills development and the program evaluation. This is consistent with Jamkrajang (2011) research titled The Development of Team building Strategic Skills of the Administrators in the Primary Schools Under the Office of Basic Educational Services, contained 5 elements in the program: background and significance of the program, program objectives, styles and development method, program structure and content of the program. Pannuek (2011) titled The Competency Enhancement Program for School Administrators Under the Office of Basic Education Service consisted of 4 parts: introduction, enhancement program content, competency evaluation and guidelines, conditions and indicators. Anuntawilailaka (2013) researched the work titled The Successfulness Team building Leadership Enhancement Program for School Administrators presented 3 projects: the strategic leadership enhancement program containing 7 handbooks, the development of the schools toward the highest competency organization having 1 manual, creating the strategic leadership network with 1 handbook. As seen in Huadsri's (2013) research titled On-The-Job Training Leadership Enhancement Program for Administrators Under the Office of Basic Education Services offered 4 parts: introduction, content of the development program, onsite efficiency evaluation tool, and guidelines, conditions and indicators for the on-the-job training leadership enhancement program. This is consistent with Khemlai (2014) research on The Development Program to Enhancement Effective Team Building for the School Administrators presented 6 elements of the program: introduction, objectives, content, activities, learning media and program measurement and evaluation.

\subsection{Results of Team Building Leadership Skills of Primary School Administrator Enhancement Program Application}

The primary school administrator had 12.00 out of 30 score points at average before receiving the development equate to 42.28 percent, and had 26.50 out of 30 score points after the development equated to 88.46 percent. The after development score point was higher than the before development average score at the statistical significant level of .01 and passed 80 percent standard set. Aemeam (2014) researched the Developing a Model of Team Building competency at the Secondary School and found that the administrators who received self-evaluation and evaluation by supervisors, subordinates and colleagues had higher team building competency after the development than before the development at the statistical significant level of .01. Moreover, Kumso (2015) research titled Developing a Team Empowerment Program in the Primary Schools Under the Office of Basic Educational Services discovered the test score on the visionary focus leadership of the primary schools under the office of basic educational services at 16.73 out of 30 score points equating to 58.11 percent while the score after the development was 27.00 out 30 score points equating to 88.77 percent. All administrators passed 80 percent standard set.

The evaluation of team building leadership skills level of primary school administrator, measured by the head administrators and colleagues, revealed that the post-development team building leadership skills level was higher than the pre-development level in all aspects. Feedback and follow up-period evaluation of the team building leadership skills level was higher than the post- development level in all aspects. This might have resulted because the primary school administrator kept searching for new knowledge though were deficient in organizational best practice, clear vision, creating values and organizational culture, staff acceptance and respects, enhance performance teamwork by engaging the tasks at hand, reflecting on their performance team, process and strategies, management, team learning and team dynamics. Team building leadership skills of primary school administrator was at a high level because they realize that the school administrators could commit, communicate with both internal and external organization staff, engaging the task and reflecting on the performance of those tasks. Success in tackling a challenging task with meaningful roles produces trust, caring and support for one another. However, the primary school administrators evaluated themselves in the aspect of team building leadership skills was at a high level since they see themselves understanding the context of both internal and external organizations, and analyze the context to develop and create team in organizations. The primary school administrators thought they were lacking new knowledge about best practices for team building skills in organization. Team building leadership skill is at a moderate level because the primary school administrators see themselves lacking team building skill, paying attention in balancing between teamwork and personal life, confidence, clear organization directions and community participation in the future of teamwork planning, research and development, resource management inefficient, communication and mutual understanding with both external and internal organizations.

They should support proactive motivation and commitments to achieving departmental objectives, establishes and communicate team goals, agree ground rules for working together as a team, ensure the correct balance and 
composition of the team, help team members to get to know each other and the strengths they bring to the team, establish clear roles and responsibilities, consult with the team, listen and act on ideas for improvement, anticipate and resolve conflict and disagreements, facilitate and ensure effective communication both within and outside the team, identify and development the overall progress of the team and recognize success. There are lacking of a checking system and frequent educational improvement. Considering the aspect of team building leadership skills, it is revealed that the school administrators fail to discuss building and leading high performing teams in school organization, check teamwork results and evaluate the information gained to develop and improve their achievement, feedback and exchange knowledge in organization. However, the evaluation and measurement after the development was at a very high level overall. The evaluation of team building leadership skills level after the development and the following stages was at a very high level. To compare, team building leadership skills level after the development was higher than before in all aspects and the level was also even higher during the follow-up period. Julsuwan (2011) studying the development of change focus leadership of supporting department administrators at the government university, showing that the change focus leadership after the development was higher than before the development with statistical significance level of 0.01 . This is consistent Anuntawilailaka (2013) researched the work titled The Successfulness Team Building Leadership Enhancement Program for School Administrators there was shown higher level of team building skills among the school administrators attending the development program in all skill types at the statistical significance level of 0.01. Aemeam (2014) researched the Developing a Model of Team Building competency at the Secondary School found higher level of strategic leadership among the administrators attending the development program in all skill types at the statistical significance level of 0.01.This is consistent Khaklong's (2014) research on The Development of Service Based Strategic Leadership Enhancement for the School Administrators Under the Basic Educational Services presented the leadership level, as evaluated by itself and by the vice directors and head teachers from academic department at overall high level, and after the development the leadership skill was higher than before at a significant level of .01. Jhunthai (2015) research titled The Development of Program of Team Development in Municipality School as was at a high level before the development and later increased after the development. It was even higher during the period of follow-up compared to after the development Also, Kumso (2015) research titled Developing a Team Empowerment Program in the Primary Schools Under the Office of Basic Educational Services was at a high level before the development and later increased after the development. It was even higher during the period of follow-up compared to after the development.

The evaluation of the team building leadership skills enhancement program in terms of satisfaction was at a very high level overall but when considering each aspect ranking from high to low the elements of training venue and facilities and development activities toolkits were at a very high level while the content and training document was at a high level. Similarly, Kidrungruang's (2008) research titled The Development and Evaluation of an Applied Program for Basic Education Institutes Self-Developing Program presented the program satisfaction evaluation as overall and in each aspect high and very high. The same results presented in the research titled Development of Creativity Leadership of the School Administrators Under the Office of Suratthani Basic Educational Service Area Zone 3, by Jankaew (2012) found that the teachers and students were satisfied with the creativity leadership of the school administrator performance at a high level. Yodsala's (2013) research titled The Development of Visionary Based Strategic Leadership of the Administrators in the Primary Schools Under the Office of Basic Educational Services found the satisfaction of the participants in the development program as high overall and the research on The Development of Service Based Strategic Leadership Enhancement for the School Administrators Under the Basic Educational Services by Khaklong (2014) found that the satisfaction of the participants in the development program as high overall and in all aspects.

\section{Conclusion}

The development research on development of program to enhance team building leadership skills of primary school administrators under the Office of Basic Education Commission Thailand concluded that:

1) There were 5 main components and 21 sub-components discovered at issue.

2) It was found that the current states on team building leadership skills of primary school administrators were implemented at a moderate level overall and in each aspect and the desirable states were implemented at the highest level in overall and in each aspect. As regards the need priority in developing the team building leadership skills of primary school administrators was ranked from highest to low were norming, performing, forming, team feedback and dynamic and storming.

3) The developed program of team building leadership skills of primary school administrator enhancement consisted of 2 items: 1) the program of team building leadership skills of primary school administrators 
enhancement contained the following: 1) program principles; 2) program objectives; 3) program resources; 4) program toolkit which consisted of 5 toolkits as the forming toolkit, storming toolkit, norming toolkit, performing toolkit and team feedback and dynamic toolkit in which there were 5 parts (introduction, background, principle to practice, lesson summary and evaluation) inclusive in each activity toolkit. The program toolkit to develop team building leadership skills of primary school administrators were various in order to create a body of knowledge, understanding, skills for team building leadership skills and continuous self-development, site visit and discussion of role models. The toolkits were consisted of 4 parts and taking 240 hours of training. 2) the program manual, which contained 4 parts: introduction, the team building leadership skills of primary school administrators enhancement program, the application of team building leadership skills development and the program evaluation.

4) Results of team building leadership skills of primary school administrator enhancement program application showed that the primary school administrator had higher score points after the development in all aspects, and at the statistically significant level of .01 , and passed 80 percent standard set. Team building leadership skills level of primary school administrator, evaluated by the administrators and teachers was higher than the pre-development level in all aspects. Moreover, the feedback and follow up-period evaluation of the team building leadership skills level was higher than the post- development level in all aspects. The satisfaction of the strategic leadership enhancement program was at a very high level overall.

\section{References}

Aemaeim, J. (2009). Developing a Model of Team Building competency at the Secondary School (Doctor of Education thesis in Educational Administration, Faculty of Education, Mahasarakham University).

Anuntawilailaka, U. (2013). The Successfulness Team Building Leadership Enhancement Program for School Administrator. Education Journal: Graduate Research, 11, 3.

Biech, E. (2008). Successful Team-Building Tools: Best of the Annuals. U.S.A: John Wiley \& Sons Inc.

Chareonwongsak, K. (2013). Team building leadership in organizational. Bangkok: Success Media.

Cheamchoi, S. (2012). Innovation of Team Building in The 21st Century School. Education Journal: Graduate Research, 14, 2.

Chris, H. (2010). Building innovative teams: Strategies and tools for developing and integrating high performance innovative groups. New York: Palgrave Macmillan.

DuBrin, A. J. (2012). Essentials of Management (9th ed.). South-Western: Cengage Learning.

Dyer Jr. W. G., Dyer, J. H., Dyer, W. G. (2013). Team Building Proven Strategies for Improving Team Performance (5th ed). San Francisco: Jossey-Bass.

Eckes, G. (2003). Six sigma team dynamics: The elusive key to project success. Canada: John Wiley \& Sons, Inc.

Edmondson, A. C. (2013). Teaming: how organizations learn, innovate, and compete in the knowledge economy. San Francisco: Jossey-Bass.

Everard, K. B., Morris, G., \& Wilson, L. (2004). Effective School Management (4th ed.). London: SAGE Publications.

George, J. M., \& Jones, J. R. (2012). Understanding and Managing: Organizational Behavior. U.S.A: Prentice Hall Publications.

Hallinger, P., \& Lee, M. (2014). Mapping instructional leadership in Thailand: Has education reform impacted principal practice. Journal of Educational Management Administration \& Leadership, 42(1), 6-29. https://doi.org/10.1177/1741143213502196

Halverson, K. B., \& Tirmizi, S. A. (2008). Effective Multicultural Teams: Theory and Practice. U.S.A.: Springer. https://doi.org/10.1007/978-1-4020-6957-4

Huadsri, S. (2013). On-The-Job Training Leadership Enhancement Program for Administrators Under the Office of Basic Education Services (Doctor of Education thesis in Educational Administration, Faculty of Education, Burapha University).

Jamkrajang, A. (2011). The Development of Team building Strategic Skills of the Administrators in the Primary Schools Under the Office of Basic Educational Services. Education Journal: Graduate Research, 6, 2.

Jankaew. (2012). Development of Creativity Leadership of the School Administrators Under to Office of Suratthani Basic Educational Service Area Zone 3 (Doctor of Education in Educational Administration, 
Faculty of Education, Rangsit University).

Jennings, M. (2008). Dynamic educational leadership teams: from mine to ours. United Kingdom: Rowman \& Littlefield.

Jhunthai, P. (2015). The Development of Program of Team Development in Municipality School (Doctor of Education thesis in Educational Administration, Faculty of Education, Mahasarakham University).

Julsuwan, S. (2011). Development of Change Focus Leadership in the Supporting Department Administrators at the Government Universities (Doctor of Education thesis in Educational Administration, Faculty of Education, Mahasarakham University).

Kayser, T. A. (2011). Building Team Power: How to Unleash the Collaborative Genius of Teams for Increased Engagement, Productivity, and Results. New York: McGraw Hill.

Khaklong, C. (2014). Development of Service Based Strategic Leadership Enhancement for the School Administrators under the Basic Educational Services (Doctor of Education thesis in Educational Administration, Faculty of Education, Mahasarakham University).

Khemlai, M. (2014). The Development Program to Enhancement Effective Team Building for the School Administrators. Education Journal: Graduate Research, 29, 4.

Kidrungruang, S. (2008). The Development and Evaluation of an Applied Program for Basic Education Institutes Self-Developing Program (Doctor of Education thesis in Educational Administration, Graduate School, Khon Kaen University).

Kohn, S. E. (2007). Six Habits of highly effective teams. U.S.A.: Career Press, Inc.

Kumso, S. (2015). Developing a Team Empowerment Program in the Primary Schools Under the Office of Basic Educational Services (Doctor of Education thesis in Educational Administration, Faculty of Education, Mahasarakham University).

Levi, D. (2014). Group dynamics for teams. California: SAGE Publications.

Lunenburg, F. C. (2015). Developing High Performance Teams: Long-Standing Principles That Work. International Journal of Organizational behavior in Educational, 3, 1.

Marquardt, M. (2011). Global teams: How top multinationals span boundaries and cultures with high speed Teamwork. USA: Davies-Black Press, Inc.

Ministry of Education. (2012). 11th Educational Development Plan (2012-2016). Bangkok: Ministry of Education.

Monique, \& Zeebroeck (2010). Teamwork Setting: the Standard for Collaborative Leading. Portland: National Middle School Association.

Ngamkanok, S. (2007). Team building. Education Journal: Graduate Research, 19, 1.

Office of the Basic Education Commission. (2013). Basic Educational Development Plan. Bangkok: Ministry of Education.

Office of the Education Council. (2014). Educational Development Report 2014. Bangkok: Ministry of Education.

Pannuek. (2011). Leadership Enhancement Program for School Administrators under the Office of Basic Education Service (Doctor of Education thesis in Educational Administration, Graduate School, Khon Kaen University).

Parker, G. M. (2007). Team Players and Teamwork second Edition. USA: John Wiley \& Sons Inc.

Phanich, W. (2012). Keys Effective School Administration. Bangkok: Sahamit Printing.

Robbins, S. P. (2013). Organizational behavior. New York: Pearson Publications.

Schermerhorn, J. R. (2015). Organizational Behavior. U.S.A.: John Wiley \& Sons Inc.

Schwarz, R. (2013). Smart leaders, smarter teams: how you and your team get unstuck to get results. U.S.A.: Jossey-Bass.

Sheard, G., Kakabadse, A., \& Kakabadse, N. (2009). Leadership teams: Developing and sustaining high performance. New York: Palgrave Macmillan. https://doi.org/10.1057/9780230239487

Sreesumphun, L. (2010). Effective Team building Skills of School Administrator in Secondary School (Doctor of 
Education thesis in Educational Administration, Faculty of Education, Ratchaphruek College).

Tranter, S., \& Percival, A. (2006). Performance management in schools: unlocking your team potential. New York: Pearson Publications.

West, M. A. (2012). The essentials of team working: international perspectives. U.S.A: John Wiley \& Sons Inc.

Whetten, D. A., \& Cameron, K. S. (2011). Developing management skills (8th ed.). U.S.A: Prentice Hall Publications.

Woodcock, M., \& Francis, D. (2008). Team Metrics Resources for Measuring and Improving Team Performance. USA: HRD Press, Inc Publications.

Yodsala, S. (2013). Development of Visionary Based Leadership of the Administrators in the Primary Schools under the Office of Basic Educational Services (Doctor of Education thesis in Educational Administration and Development, Faculty of Education, Mahasarakham University).

Yuk1, G. A. (2010). Leadership in organizations (7th ed.). U.S.A.: Pearson Prentice Hall Publications.

\section{Copyrights}

Copyright for this article is retained by the author(s), with first publication rights granted to the journal.

This is an open-access article distributed under the terms and conditions of the Creative Commons Attribution license (http://creativecommons.org/licenses/by/4.0/). 